\title{
Putting the Right Face on a Wrong Body
}

\section{An Initial Interpretation of Fat Identities in Social Work Organizations}

Mik-Meyer, Nanna

Document Version

Accepted author manuscript

Published in:

Qualitative Social Work

DOI:

$10.1177 / 1473325010367817$

Publication date:

2010

License

Unspecified

Citation for published version (APA):

Mik-Meyer, N. (2010). Putting the Right Face on a Wrong Body: An Initial Interpretation of Fat Identities in Social Work Organizations. Qualitative Social Work, 9(3), 385-405. https://doi.org/10.1177/1473325010367817

Link to publication in CBS Research Portal

\section{General rights}

Copyright and moral rights for the publications made accessible in the public portal are retained by the authors and/or other copyright owners and it is a condition of accessing publications that users recognise and abide by the legal requirements associated with these rights.

Take down policy

If you believe that this document breaches copyright please contact us (research.lib@cbs.dk) providing details, and we will remove access to the work immediately and investigate your claim. 
Final version before publishing. Full reference: Mik-Meyer, N. (2011) Putting the right face on a wrong body: An initial interpretation of fat identities in social work organizations, Qualitative Social Work, 9(3): $385-405$.

PUTTING THE RIGHT FACE ON A WRONG BODY: AN INITIAL INTERPRETATION OF FAT IDENTITIES IN SOCIAL WORK ORGANIZATIONS

\author{
Nanna Mik-Meyer ${ }^{1}$ \\ Copenhagen Business School, Denmark
}

1 Please direct correspondence to Nanna Mik-Meyer, Department of Organization, Copenhagen Business School, Kilevej 14A, 4th floor, 2000-Frederiksberg C, Denmark; email: nmm.ioa@cbs.dk. 


\title{
PUTTING THE RIGHT FACE ON A WRONG BODY: AN INITIAL INTERPRETATION OF FAT
}

\section{IDENTITIES IN SOCIAL WORK ORGANIZATIONS}

\begin{abstract}
In recent years obesity has emerged as a potential public health crisis. This article examines how being overweight is framed as a social problem in two public Danish organizations. Using recorded interactions between health consultants and overweight people, this article explores how overweight people develop a sense of self in weight loss programmes. This article uses an interactionist approach in exploring the dual nature of identities involving both the self and social structure. Drawing on sociological literature concerning the relationship between the body, health, risk and society, this paper shows how overweight people in western society are currently perceived as being morally inferior. This societal context frames the participating organizations that offer weight loss programmes to overweight people, and hence results in organizational identities that equate being overweight with having psychological problems. The analysis in this article shows the importance of situating identity processes in the organizational framework in which they occur and situating organizations in a broader societal framework that casts some people as morally inferior and others as 'normal'.
\end{abstract}

Keywords: body sociology, fat/overweight, health, identity processes, interaction, organizations 


\section{PUTTING THE RIGHT FACE ON A WRONG BODY: AN INITIAL INTERPRETATION OF FAT}

\section{IDENTITIES IN SOCIAL WORK ORGANIZATIONS}

\section{INTRODUCTION}

In recent years, being overweight have emerged as a factor in a potential public health crisis in western societies, leading to social workers being increasingly called upon to focus on this specific group. Social workers, taking on the role of health consultants, employ a range of different techniques in their work with overweight persons. This article presents ways in which overweight people develop a sense of self in public organizations working with weight loss.

Academic interest in identity processes has grown within social work (e.g. Butler et al., 2007; Holstein and Gubrium, 2000; Hjo rne, 2005; Juhila, 2004; Urek, 2005). The relationship between identity processes and the body in organizations is of course not an altogether new research focus. Gender studies, for example, have focused on the gender identities produced in organizations (e.g. Adkins, 1995; Townsley, 2003; Wilson, 1996), while race and sexuality have attracted attention in organizational research (e.g. Deitch et al., 2003; Ward and Winstanley, 2003). The overweight body, however, remain under-theorized both in the area of social work and organizational studies: the overweight body has become an 'absent presence' (Shilling, 1994: 19) in contemporary research on identity negotiations (Barry and Hazen, 1996 cited in Hassard et al., 2000: 4; Trethewey, 1999; Valentine, 2002).

Today, much social work in public organizations focuses on the health of their clients, including the clients' body weight. While the overweight has become a problem in society at large, this article specifically examines identity processes that target the overweight body in public organizations. This is a new and growing field within social work. Besides drawing attention to the corporeal body, I pay particular attention to the interactional aspect of identity formations by bringing Goffman's concept of 'face' into the analysis. While symbolic interactionism, and especially Goffman's term 'impression management', has informed much organizational research (e.g. Czarniawska-Joerges and Jacobsson, 1995; Steyrer, 1998), few organizational studies targeting social work issues have looked closely at face-to-face interactions, i.e. 
the dialogue occurring between research participants, in order to show how the dynamics of different situations interconnect to 'a larger swath of time and space' (Collins, 2004: 5).

Research on organization and identity inspired by an interactionist approach is either generalized to an organizational level (e.g. Hatch and Schultz, 2002) or - when reporting empirical findings - conducted using observation notes and/or interviews (e.g. Dick, 2005; Down and Reveley, 2004; Heracleous and Marshak, 2004; Samra-Fredericks, 2004). This article, however, analyses how institutional identities like fat identities are negotiated in social work ${ }^{2}$, i.e. the actual social process of identity formation. Furthermore, it examines how overweight people develop a sense of self in interaction with the social environment within organizations.

As varied as the aforementioned studies are, both empirically and theoretically, they are all informed by a constructivist or, as some prefer to call it, a postmodern research strategy (cf. e.g. Brown, 2001). By 'constructivist' or 'post- modern', I mean that these studies conceive of identity as social and relational, i.e. formed and negotiated in the presence of other social actors. Taking a symbolic interactionist approach, identity is not construed as a substance or a core that human beings carry around; rather, identity is viewed as a social process undergoing constant change, making the social surroundings in which the identity negotiations evolve central in the analysis. Identity work involves the exchange of symbols accentuating both 'specific others' (e.g. social actors in an organization) and 'generalized others' (e.g. norms and values in society) (Mead, 1959). Applying this anti-essentialist approach to identity work, I examine how a powerful, dominant discourse about human health is negotiated in practice by health consultants and overweight persons and how this discourse is thus both constitutive of and constitutive for practice. Individual persons 'the specific other' - are positioned as persons with a problematic psyche: 'the generalized other'.

To sum up, this article departs from previous analyses of identity processes within the area of social work in two ways: (1) the objects of analysis are the overweight body in organizations and how this specific body is framed as a social problem, and (2) the fruitfulness is shown of combining research on identity work in organizations with symbolic interactionism and current sociological research on the body and society (e.g. Rose, 2001; Turner, 2003). The purpose of combining these approaches is to illustrate the dual nature of identity, implying both a self and social structure. In accordance with other critiques of the 
'narrowness' of symbolic interactionist studies (for a discussion of this critique, see Maines, 2003), I situate my analysis in the context of a broader sociological analysis of present western societies where a dominant health discourse subscribes to a set of moral judgments that engender specific conceptualizations of the 'normal' body.

\section{BODY, HEALTH AND SOCIETY: THE SOCIETAL CONTEXT OF IDENTITY NEGOTIATIONS IN}

\section{ORGANIZATIONS}

Western societies are currently witnessing a 'valorisation of health' (Greco, 2004: 1) that influences people as well as organizations. People are expected to have a 'drive for health, accepting their responsibility for securing their own well-being. Organisations and communities are also urged to take an active role in securing the health and well-being of their employees and members' (Rose, 2001: 6). Indeed, as Greco (2004: 1) argues, health policies today are 'endorsed as a kind of meta-value, and speaking in the name of health is one of the most powerful rhetorical devices'.

Health, however, apart from being an individual right in present society, can also be viewed as a duty, enforced through subordination to authority (Greco, 2004: 2). Thus, the body can be understood as a locus of power, which is why specific types of bodies in specific time periods are defined as 'normal' and other bodies are defined as 'abnormal' (Blaikie et al., 2004). Constantly recreated, regulated and influenced by dominating social and cultural discourses, the fat body is hence not conceptualized foremost as a biological phenomenon, but as a social and cultural one (e.g. Bordo, 1993; LeBesco, 2004; Orbach, 1978). Politics of fatness and fat bodies 'operate as a nexus of power where we can observe national angst and new instantiations of racism and sexism being played out within individual lives' (Herdon, 2005: 129). A essential point in constructionist inspired research on the relation between body and society is that the body is seen to be an 'unfinished entity' (Shilling, 1994) and that research on fatness, for example, therefore needs to look at how perception of the body is stabilized in different social environments (Mik-Meyer, 2010).

In Weighing Health: The Moral Burden of Obesity, Jutel (2005) discusses how obese and overweight people are continuously constructed as being morally inferior people with a problematic psychological situation. Or, as Turner (2003: 2) states, 'Obesity is a loss of sovereignty over the body and it 
has typically been regarded as both a measure of moral laxity in the individual and a sign of social corruption'. Many researchers argue that fatness presumes moral deviance and is conceptualized as a disease of the will, a psychological pathology. Fatness is equated with a lack of self-discipline, control and willpower (Jutel, 2005; Monaghan, 2005; Murray, 2005).

Presently in western society, being fat is thus not only perceived to be medically unhealthy, but also as morally unhealthy. A fat body is inferior to a 'normal', slim body (Jutel, 2005) and is taken to be inhabited by persons who lack self-control and willpower. As such, fat bodies provoke the fundamental idea that one ought to want to be healthy, that one ought to have the motivation to be healthy (Greco, 2004; Murray, 2005; Rose, 2001). It is not only fatness conceived as a disease of the will that threaten citizens of western countries, however, in more general terms the body is currently perceived as a site upon in which any number illnesses may occur (Novas and Rose, 2000). Turner (1992: 1ff; 2003: 6) uses the concept of 'the somatic society' to direct attention to how political and social anxieties are transferred to the body, just as Novas and Rose (2000) define contemporary people in western societies as 'somatic individuals', i.e. individuals who are defined first and foremost by their 'potentiality' to become sick. In both cases, the focus is on how the corporeal body is understood and translated in a specific societal (and hence organizational) context that today connects to a health discourse that labels overweight and fat people primarily as persons with a psychological problem.

\section{IDENTITY AS AN INTERACTIONIST ACCOMPLISHMENT}

As presently applied by symbolic interactionist scholars, the concept of 'institutional identity' captures the relational aspect of identity formation. This paper focuses on how an organizational setting provides actors with different identities; modern people do not live out one identity, but many identities within the different organizational frameworks of which they are part (Gubrium and Holstein, 2001). In Stigma, Goffman (1965) made clear that any negative identity, for example, being overweight or fat, reveals information about the relationship between dominating norms and values in society and the specific characteristics of a group.

Viewing overweight people as having a problematic psyche, i.e. as being weak willed, out of control, lacking self-discipline, etc., makes working with these individuals' psychological situation 'natural'. 
According to Goffman, however, doing so directs attention to the wrong unit. He argues that the meaning of any negative identity, such as being overweight, has to be found in the relationship between those who are overweight and the dominating norms and values in society - norms and values that exclude this group by maintaining their status as one that is less human. For Goffman (1965: 51), 'stigma management is an offshoot of something basic in society, the stereotyping or "profiling"' of our normative expectations regarding conduct and character'. Any organizational frame positions the actors with distinctive moral characters (Goffman, 1990: 24). When an overweight person interacts with a health consultant in an organizational framework focusing on the overweight person's obligation (or will) to become healthy (i.e. to lose weight), both individuals are positioned as particular types, i.e. assigned specific moral characters which reflect the specific organizational framework or 'definition of situation'.

Goffman, of course, focuses strongly on the social order in different situations, showing how in their orientation toward each other during interaction, people will reproduce (or even sometimes try to alter) the prevailing social order. He uses the concept of 'misrepresentations' (Goffman, 1990: 65ff.) to direct attention to fact that people sometimes encounter 'wrong faces' (Goffman, 1967: 5) compared to the specific context. Overweight people who present themselves as being wilful and in-control, or who simply refuse to accept an identity that labels them as a person with a psychological problem, constitutes such an encounter. Having the 'wrong face', and hence balking at the predefined aspects of the situation, thus leads the other participants in the situation to work harder to reach a joint 'definition of situation'. These kinds of situations do happen, of course, but since they are universally recognisable as atypical, and since every society has 'institutional authorities', i.e. persons who because of their position can give an official version of reality (Goffman, 1983: 17), the concepts of 'misrepresentations' and 'wrong face' furthermore highlight the power structure of any situation.

Interaction between people in an organizational framework is thus carried out to fit with the understanding and expectations that constitute the society and specific organizational framework in which it is part. In other words, human beings are continually preoccupied with adjusting their behaviour so that they and other social actors can keep up and reproduce the specific social order that reflects societal norms and values, and which in this case, casts overweight and fat people as having psychological problems (e.g. Jutel, 
2005; Monaghan, 2005; Murray, 2005; Turner, 2003). When analysing the negotiation of identities in organizations, it is important to remember that it is not a question of dealing with 'men and their moments, but moments and their men' (Goffman, 1967: preface). After a short contextualization of this study, I examine the identities that organizational 'moments' of fatness in social work accomplish.

\section{CONTEXTUALIZING THE STUDY}

Currently, a variety of health initiatives exist in western countries to counteract a further increase in the number of overweight and obese people. In 2000, for example, a National Obesity Forum was established in England to create recognition of obesity as a serious medical problem and to convince the government to make fighting obesity a national priority. Obesity is considered a public health time bomb (National Obesity Forum, 2007) with one doomsday scenario suggesting that Britain will be populated exclusively by obese people by 2030. In the USA, President George Bush declared a War on Fat in a nationally broadcast speech on the radio on 22 June 2002 (Herdon, 2005: 133). The World Health Organization (WHO) declares that 'obesity in Europe has reached epidemic proportions' and is therefore believed to be 'one of the greatest public health challenges of the 21 st century' (http://www.euro.who.int/obesity, consulted Jan. 2008). Half of all adults in the WHO European Region are overweight and this is believed to strongly affect economic and social development (WHO, 2006).

Denmark is also experiencing growth in the number of overweight and obese people, leading Danish politicians to propose a variety of programmes to deal with the problem. National health plans have been developed stressing that counteracting overweight and obesity in the population is a multi-sector responsibility involving government initiatives, private and public work organizations, schools, health services and others (Danish Ministry of the Interior and Health, 2002). Denmark is thus working in accordance with the WHO's (2006: 4) recommendations to take action at both micro and macro levels that involve organizations as diverse as 'families, communities, kindergartens, schools, workplaces' to counteract overweight and obesity.

To confront the increase in the number of overweight people in Denmark, many welfare organizations have started to focus on the risk factors involved in the lifestyles of overweight people. These 
initiatives can be seen both as a result of a governmental initiative (the actual activities are often financed or partially financed by the state) and as a result of a new way for organizations to brand themselves, i.e. by highlighting activities that focus on employees' health. One tool employed is the 'personal health conversation'. During the conversations the overweight person describes his or her lifestyle, including eating, smoking and drinking habits, as well as his/her psychological situation, while a health consultant provides health improvement advice.

\section{DATA AND METHODOLOGY}

This paper draws on a two-year research project on overweight and fatness in Denmark initiated in 2005. The main study consists of a qualitative, ethnographic approach comprised of participant observation, recorded conversations between health consultants and overweight persons (where I was not present), interviews with health consultants and overweight persons, and documents and interviews from different participating organizations and the political world.

In this paper, I draw exclusively on 26 recorded personal health conversations between overweight persons and health consultants in two programmes targeting overweight persons. Since my goal is to analyse the relations between dominant discourses about health and interactions between overweight persons and health consultants, I have consciously excluded material in which I have been a co-producer (e.g. interviews and field notes $)^{2}$. In the present analysis I have excluded interview material and general observation material, although I am aware that this material illustrates other ways in which identities are constantly reproduced in different social settings. My choice of only using recorded conversations in this paper reflects my desire to be able to work, in depth, with a large amount of material. The recorded conversations, however, are naturally perceived as a social text (cf. Holstein and Gubrium, 1997: 116). The data have been selected and analysed by me in accordance with the focus on identity negotiations of this study.

The personal health conversations were recorded in one mid-sized (Programme 1) and one large (Programme 2) municipality in Denmark. Initially, I learned about the two programmes aimed at overweight persons from a health consultant I met at a conference on health issues in Denmark. After the 
conference, I did an Internet-based search to see how common these types of programmes were and how they were organized by comparing activities, goals, target groups, educational background of staff, etc. I found that many mid-sized and large municipalities had special programmes for overweight persons that were quite similar in relation to the themes just mentioned. I chose two programmes that exemplified the most common way of dealing with weight issues in a public organization. Their activities included a mixture of physical training and/or social and psychologically oriented activities. Primarily, their goal was to help overweight persons lose weight, but most often the programme's goals also specified that the participant would go through a positive psychological development. The staff, which contained mainly of women, had medium length education in the social and health sector, for example trained as social workers or physiotherapists. The first group of overweight participants was employees working in the service or trade sector who had a short or medium length education. They had been granted a series of personal health conversations from their employers (Programme 1). The second group of overweight people had work experience in the service or trade sector and had either a short or no education. They had recently left the labour market and had been granted permission to participate in a full-time weight loss programme involving a combination of physical training and personal development activities from the social system (Programme 2).

After presenting my research project to the health consultants in the two programmes, they agreed to record their conversations with overweight people. Several days prior to the conversation, each overweight participant from the programmes in the two municipalities received a letter about my research stressing that participation would be welcome but only by consent (all the participants were invited by their health consultants). In the letter I explained that participants would be anonymous and that they had the right to change their minds about allowing me to have the recording after the conversation (an option no one took advantage of).

The recorded conversations last approximately one hour each. I received 18 recordings from Programme 1 and 8 from Programme 2, each of which I listened to twice. The first time I listened to them, I wrote down the themes that were discussed while the tape played; afterwards, I listened to them again in order to list the time to show precisely which part of the conversations I wanted to have transcribed. The 
only parts not included in the transcriptions are dialogues by the health consultant on nutritional matters. In general, approximately 20 to 40 minutes of each conversation were transcribed.

At the time of the analysis, I had 26 recorded conversations that met my criteria for length (a few conversations lasted less than 15 minutes and were discarded because they were brief follow-up conversations on the participants' medical history). Although each of the 26 conversations have been analysed, the analysis in this article explicitly cites only 8 conversations. The conversations selected illustrate common patterns found in the whole body of material with respect to the individuals chosen and the themes discussed. Twenty-two out of the 26 overweight participants were women and 4 were men ${ }^{3}$. Two persons were in their 60s and the rest were in their 40s and 50s, and they were all ethnic Danes. Seven out of the eight people quoted in this article were women and one a man. This group from which quotes were taken was also ethnic Danes in their 40s and 50s at the time of the recording. The participating health consultants, all educated in social and healthcare areas, were two women (health consultant A and B) and a man (health consultant C). The conversations selected were chosen because they reflect a common pattern in the interactions within all the recorded interactions, namely that being overweight is associated with having psychological problems. Each conversation includes dialogues concerning the overweight person's psychological profile that, of course, can also be a result of the programmes' activities.

In the two programmes the health consultants defined overweight persons as persons with a psychologically problematic situation, which the programmes' activities clearly illustrate: in Programme 1, health consultant A was able to help make appointments with a psychologist if considered necessary by the health consultant and/or the overweight person. In Programme 2, health consultants B and C offered to make an appointment with a psychologist working in the programme as well as group conversations about private issues considered difficult to deal with for the overweight person. The association between being overweight and having a problematic psychological profile was also clear from the issues discussed in the conversations between health consultants and the people who were overweight. These conversations often revolved around discussions about the overweight person's psychological profile.

Every one of the participating overweight persons voluntarily chose to participate in, typically, three or four personal health conversations, and in Programme 2, they also chose to participate in 
group discussions about personal issues. These activities demonstrate the current 'naturalness' of linking being overweight with psychological problems. Being overweight was generally seen as a physical and psychological health threat, even though none of the participants, for example, suffered from severe illnesses due to their excess weight. The programmes' written material and discussions with the health consultants clearly show a general belief among staff that their programme's physical and psychological elements would benefit the overweight persons' further development positively.

\section{PRODUCING FAT IDENTITIES}

During the health conversations, the consultant generally asked the overweight person to elaborate on personal issues. The discussions could involve, for example, familial relationships. In one of the conversations from Programme 1, health consultant A asked an overweight woman - Anna - to debate her eating habits in relation to her relationship with her mother (e.g. 'Does your mother confront you [regarding your eating habits]?'). The conversation shows that Anna's (problematic) relationship with her mother was considered by the health consultant to be an important issue to be discussed if Anna wanted to lose weight, as is also shown by the number of questions Anna was asked regarding this issue.

The following excerpt is from a different conversation with an overweight man (Andrew) in which health consultant A asked him to reflect upon how weight loss would produce changes in his relationship with his wife (and hence changes in Andrew's personal situation):

Health consultant A: $\quad$ If I were to ask you... how you - in regard to your family, maybe in regard to your wife - would change something if you only weighed 110 kilos...would that make a change in your life together? Would you be able to do other things with your wife that you are unable to do today... hmm...?

Andrew: Hmm... well... our sex life would be better [giggling], that could be part of a change... 
Health consultant A: $\quad$ It could be part of a change that meant you were more active in bed, or...?

Andrew: $\quad$ Hmm... yes...

Very personal questions, such as indirect questions about the overweight person's sex life, as in Andrew's case, were not uncommon in the conversations. These personal questions - often framed as discretely as with Andrew - would frequently surprise the overweight person (documented by a pause in the conversation and/or by giggling). A giggling response can be viewed as a way of coping with a difficult situation produced, in this case, by questions covering very personal issues from a public organization where no one necessarily expects the focus to be on personal, intimate issues (cf. Douglas' [1999] 'joke in the social structure' that generates laughter; Mik-Meyer, 2007).

In a conversation with an overweight woman - Mary - health consultant A asked Mary to elaborate on her relationship with her boyfriend, Peter. The health consultant asked a number of follow up questions concerning how Mary thought Peter would evaluate her 'mood' and 'temperament' in general. The health consultant asked if Mary thought her weight loss had improved her mood and temperament, making them more positive than before she started in the programme. In other conversations, health consultant A asked, for example, if the overweight persons' thought they could look after themselves, and if they thought they were more selfish than other (normal sized) people. Their personal situation would, in other words, usually be discussed in contrast to an imaginary 'normal' (slim) Dane. These questions, in a variety of ways, stimulated conversation focusing on their problematic personal situation.

In a conversation with an overweight woman - Helen - the main topic concerned her taking control of her life. The health consultant suggested that Helen take better care of herself and develop a more 'selfish attitude' and 'stick to her limits'. This advice resulted from health consultant A's repeated questions on these specific (problematic) personality traits. In a different conversation between Diana (an overweight woman) and health consultant A, the result of the evaluation of Diana's personal situation was that, according to the health consultant, she needed to 'take control' and 'stick to her limits'. 
Focusing on the overweight person's (problematic) personal situation was also a typical central target of Programme 2. The next part of the analysis shows extracts from three conversations from Programme 2 that show this process in detail. Three overweight women are instructed how to put the 'right' faces on their 'wrong' bodies (cf. Goffman), just as my introductory examples from Programme 1 illustrate. In the extracts, health consultants B and C try to make three women accept different problem-oriented identities, including (1) being in a crisis, (2) being in need of 'positive thinking', and (3) accepting that a problematic body is caused by a problematic psychological situation. These identities define them as people in need of the help offered by the health consultants ${ }^{4}$.

\section{Fat identity 1: Being in a Crisis}

Indicative of the typical way a conversation begins, the first part of the conversation between an overweight woman - Suzy - and health consultant B revolves around Suzy's general opinion of the programme. Suzy explains that she is more tired now compared to when she began two weeks earlier. Prompted by the health consultant (the health consultant asks questions such as 'are you psychologically more stressed now than when you began the programme?', 'Do you need us to take extra care for you?', 'Is your image of yourself as a person with loads of energy correct, or ...?', etc.).

As a result of the health consultant's sustained interest in Suzy's psychological situation, the conversation develops into a discussion about Suzy's (problematic) personal and private life. The excerpt below starts at the point where health consultant B is about to suggest that the one and a half kilos Suzy has gained since she started the programme is a result of Suzy's 'crisis' (a term suggested by the health consultant). At the beginning of the conversation Suzy brought up the issue of her weight gain, but associated it with an increase in muscle due to exercise.

Health consultant B: $\quad$ I'm still thinking about what you said about having gained one and a half kilos - and you say it's all muscle. But you don't know if it's muscle. Do you associate the psychological aspect with your weight? 
Suzy:

Health consultant B:

Suzy:

Health consultant B:

Suzy:

Health consultant B:
Yes.

So, what do you think? Because you do work out a lot, Suzy. Yes, now I do. You know, Mondays and Wednesdays. I also eat more here, more than I usually do. So it's a combination of things.

It's a combination . . .?

Yes, it's a combination. It isn't natural for me to be fat, you know; as a child I was always thin. Then, when I moved here, I put on twenty kilos in four years. And I haven't lost them yet unfortunately...

What I think, Suzy, with all this stuff you've got going on, and so you won't start beating yourself up by saying, 'Now I'm also putting on weight!' . . Maybe you can say, 'I'm where I am right now and a lot of things keep popping up'. You are going through some crises.

This dialogue shows how the health consultant confronts Suzy's suggestion that the one and a half kilos she has gained are muscle tissue. Health consultant B suggests instead that it could be a 'psychological aspect' that has caused the weight gain. Note, however, that this suggested analysis is given cautiously ('You do work out a lot'), which can be seen as recognition of her statement that the weight gain is a result of stronger muscles. Suzy accepts this gesture by concluding that it must be 'a combination', i.e. making it possible that the weight gain is caused by the increase in exercise and her psychological situation. By repeating the combination explanation, the health consultant implies that Suzy should expand on her elaboration (which does not work as the sole explanation), which she then does. After her elaboration, the health consultant offers her view that Suzy is in crisis. 
This brief exchange of words, which lasts less than one minute, shows how health consultant $\mathrm{B}$, in her role as the institutional authority, very quickly produces the official reason for the woman's problematic weight: personal crisis. Even though this explanation differs from Suzy's own explanation, it does not occasion any resistance from her. This is probably because the organizational framework of the conversation is a programme that explicitly links being overweight with having psychological problems. This frame thus positions the health consultants and overweight persons into specific roles producing specific identities. These identities support and reproduce the social order that links the overweight persons to the idea of 'persons in crisis' and the health consultants to 'persons that should help resolve crises', and as such reproduces the organizational and societal narrative of fatness.

Fat identity 2: Needing (more) Positive Thoughts

The first exchange between an overweight woman - Ann - and health consultant C is about how Ann is doing and how she likes the programme. Ann explains that she likes to exercise and that she has developed a good rapport with four other participants in the programme. The following excerpt starts where health consultant $\mathrm{C}$ responds to Ann's positive evaluation of exercising and her social relations to other participants:

Health consultant C: $\quad$ You've really started up well; I see... with training... How are things going in terms of keeping in touch with your feelings and having positive thoughts and that kind of thing?

Ann: I don't really think - to be honest, those 'positive thoughts'.... It's not that I don't want to engage in them, or that I consciously think 'I really just don't care'...

Health consultant C: $\quad$ No, I know that... About your weight, how important is it compared to positive thinking and keeping in touch with your feelings? Do you think you can maintain your weight loss in the long run if you don't work with the other side of you...? 
Ann:

Health consultant C:

Ann:

Health consultant C:

Ann:

Health consultant C:
Well, my weight means a great deal to me...

But what's most important - to think positively and keep in touch with your feelings? Is it important to develop positively, to accomplish something in that regard? Or is it more important that you shed some weight?

It would be most important for me to lose weight, because then I'll also become more satisfied with myself...

The reason I ask is that it's important to figure out where some positive energy is stored... Because, when is enough, enough? [And no matter how much weight you lose], my guess is that you'll still have problems with your own feelings and your selfesteem that are independent of your weight.

Yes, it won't go away with the weight. It won't. But I would feel better about myself.

Yes, I understand. Anyway, it was good you joined the programme. I can sense that.

This dialogue illustrates how the health consultant needs to work a bit harder to make Ann accept that an important focus for her in the weight loss process is her psychological situation (and not solely her physical situation, which is what Ann would like to focus on).

Early in the conversation, when Ann says that she is a bit sceptical about the psychological aspect of the programme ('It's not that I don't want to engage in it...') she produces a 'wrong' face in the interaction by threatening the working definition of the situation, which assumes that the participants are unable to lose weight exclusively by exercising; they have to engage in 'positive thoughts' and be in touch with their feelings. Ann is asked to evaluate the programme, in other words, the order of interaction requires her to evaluate both the programme's emphasis on exercise and the programme's focus on the participants' psychological situation (group talks on personal issues, the personal health conversations, etc.). Ann's 
sceptical answer concerning the psychological aspect of the programmes generates the health consultant's rhetorical question about what is most important to her: to think positively and, hence, 'develop positively' and 'accomplish something' or to shed some weight? Against expectations, Ann chooses the wish to lose weight (by exercising), which requires more effort from the health consultant, who continues to try to put a fat face on a fat body, i.e. insists on the notion that being overweight is not only a question of eating and exercising habits, but also relates to the person's (problematic) psychological profile. Exercising and losing weight are not sufficient if Ann, as the health consultant says, wants to maintain her weight loss 'in the long run'.

The health consultant's response reflects the logic of the programme: in order for the participants to lose weight (in the long run) - which is an important goal of the programme - the participants have to work with their physical (exercise) and psychological (group discussions, etc.) situation. Ann does not, however, support this explanatory model; her reserved statement therefore deviates from what is expected, and veers away from putting the 'right face' offered by the health consultant on her overweight body.

Health consultant $\mathrm{C}$ then tries a different strategy by offering the right view of Ann's situation ('The reason I ask ...'), thus cornering Ann. The health consultant's institutional authority demands that she recognize the importance of working with her psychological situation if she wants to maintain her weight loss. The health consultant goes as far as to suggest that pure weight loss will not help Ann with the many other problems she has beyond her weight. Finally, although she stresses that she will also feel better if she loses weight, Ann chooses to accept that her feelings about herself are not only a matter of weight. The health consultant responds to this rather vague but cooperative gesture by pushing the aforementioned identity by saying that she understands why Ann focuses on her weight as such, but that other issues will have to be dealt with (cf. 'Anyway, it was good you joined the programme. I can sense that'). 
Fat identity 3: Accepting your Problematic Psychological Situation

In the next excerpt, health consultant B and an overweight woman - Karen - have just talked about Karen's progress. Karen explains that she now feels that she 'can control her own life', thus leading the health consultant to respond as follows:

$\begin{array}{ll}\text { Health consultant B: } & \text { Wow, huh? } \\ \text { Karen: } & \text { Yes, there's a lot going on. } \\ \text { Health consultant B: } & \text { Now that we're talking about wholeness; the body and psyche } \\ & \text { are connected. It's one thing to work with your body and } \\ & \text { exercise, but your self-esteem is also important... and my guess } \\ & \text { is that your self-esteem is strongly connected to your being } \\ & \text { overweight, or what...? } \\ \text { Karen: } & \text { Yes, it is. } \\ \text { Health consultant B: } & \text { Your mind is definitely made up about that? }\end{array}$

Karen offers a number of arguments to show that her mind is made up, leading the health consultant to make the following statement:

Health consultant B: $\quad$ I almost feel like telling you what I think about how you are doing right now, because you look like things are going really well for you.

Karen: I feel great.

Health consultant B: $\quad$ You have nice rosy cheeks and your body looks perfectly relaxed. That's the impression I'm getting. 
Karen:

Health consultant B:

Karen:

Health consultant B:
I also feel good...

When you say you think that your trousers are getting too big, and considering all the exercising you do, I think you're putting on muscle not fat.

I have actually gained one and a half kilos, but...

That's nothing to worry about.

The first acknowledgement of Karen's account of what she has learned in the programme is demonstrated by health consultant B's exclamation, 'Wow, huh?'. Using slightly different words, the health consultant repeats Karen's account, highlighting the idea that body and psyche are connected. Karen - in contrast to the two other women - is not reluctant to accept the identity as a person who needs to work on her self-esteem. Therefore, she fully supports health consultant B's transformed analysis of her situation ('Yes, it is'). The health consultant's many positive remarks about Karen ('her nice rosy cheeks... relaxed body') and her comment that the weight gain must be muscle and not fat are perhaps a way of thanking Karen for producing the right face in the interaction, i.e. for accepting the programme's and society's values, that associate a high body weight with having psychological problems.

Note that health consultant B, in her conversation with the first overweight woman, who also had gained about one and a half kilos and had also tried to relate her weight gain to larger and heavier muscles, chose not to explain the extra weight as a result of heavier muscles. With respect to Karen, who cooperates and who has accepted the connection between her large body weight and her psychological problems, however, the extra kilos are 'nothing to worry about'.

\section{CONCLUSION}

Every western country is currently witnessing an increase in the number of overweight and obese people. The societal focus on health and the increase in numbers suggest that this 'problem' will gradually become an increasingly important target in social work practices. There is therefore a need for studies that focus on 
how being overweight is being negotiated in real organizational life. For this purpose, an interactionist approach is needed.

An interactionist approach - represented here by Goffman's work - makes it possible to research how a person's fat identity connects to an organizational and societal narrative of fatness. Even though this micro sociological approach has a strong focus on the social order and a dominant definition of situation, the demands of this approach for a contextualization of the analysis and the detailed study of actual people's actions makes it possible to show how identities are being negotiated by real people in real life.

Much research has showed that fatness is often equated with laziness, a lack of control and faulty willpower (Monaghan, 2005; Murray, 2005; Turner, 2003). Some researchers suggest that fat people are constructed as being morally inferior (e.g. Jutel, 2005) because of their lack of self-discipline. This article supports these research findings. As the analysis shows, health consultants relate being overweight with having a problematic psychological situation. Overweight people are believed to have problems with their nearest relatives (mothers, spouses etc.), have a problematic 'mood' and 'temperament', lack a selfish attitude, need 'control' and 'limits', be in a 'crisis', need more 'positive thoughts' and generally are more in need of learning to accept their problematic psychological situation. This article's analysis supports the argument that being overweight is tantamount to having psychological problems.

The analysis demonstrates how this broader societal narrative concerning fatness is challenged by overweight people only to be recovered by subtle face-work that reinstalls the dominant definition of the situation. This confirms Goffman's ideas about how socially perceptive the participating actors are and how sensitive they are to putting on the wrong face (Goffman, 1967: 8). The overweight participants ultimately (if reluctantly) accept negative identities that assign them fixed positions within the dominant social order. By applying an interactionist approach that takes the situation rather than the individual as its basis (Collins, 2004: 3), I have analysed how identity negotiations in two programmes targeting overweight people relate to a societal narrative of fat persons as people in a problematic personal situation. As Collins states (2004: 5), 'a situation is not merely the result of the individual who comes into it, nor even of a combination of individuals (although it is that, too). Situations have laws or processes of their own'. In this article, I suggest that the laws of situations dealing with being overweight are associated with societal narratives of 
overweight and fat people being perceived as morally inferior (they have the wrong mood, temperament, feelings, self-esteem, personal judgement, limits, etc.).

By analysing the dynamics of situations in a specific organizational frame that conflates fatness with a range of psychological problems, I have showed how overweight people are transformed from people with an overweight body to people in a crisis. An interactionist approach can thus show both the instability of identities (Gabriel's [1999] struggling, feeling and suffering subject) and the control aspect of any organizational framework that produces specific 'moral characters' and hence supports specific institutional identities.

I have tried to demonstrate how societal and organizational mechanisms centred on a 'normal' body work as a subtle form of control positioning, in this case, both health consultants and overweight persons. Both groups are assigned specific moral characters produced by the organizational and societal contexts. By using the concept of face, it becomes clear that identity must be understood and analysed as a social accomplishment that derives from each participating actors involved in negotiating the particular identity and should hence be understood and analysed as more than a social process of the specific social actor bearing the identity.

The focus of this article on the corporeal body in two Danish programmes targeting overweight persons illustrates that the negotiation of a person's identity indeed relates to the specific organizational context. The cases presented show that the negotiation of fat identities proceeds from a conviction that an overweight person should not only struggle with excessive body fat but also with a range of psychological problems (documented by the programmes' activities). The management of the fat body in organizations is linked to a societal narrative of fat people as being afflicted. The analysis in this article therefore confirms the importance of situating identity processes in the organizational framework in which they occur and of situating organizations in a broader societal framework that appraises specific values casting some people as morally inferior and others as 'normal'. 


\section{ACKNOWLEDGEMENTS}

I want to thank the anonymous reviewers for Qualitative Social Work for very concrete and helpful comments.

\section{NOTES}

1 I am using the terms 'overweight' and 'fat' in this article interchangeably because both terms are commonly used by the persons carrying the extra kilos and the health consultants, and are used in the media and in the political world. The term 'obesity' is rarely used in Denmark (except in medical documents). 2 One limitation of the analysis is that only the verbal interaction was analysed. Symbolic interactionism, of course, offers many other tools that can be beneficially applied to non-verbal interaction. My focus on verbal interaction, however, provided me opportunity to record and transcribe conversations uninfluenced by my presence.

3 As the amount indicates, more women participate in personal health conversations than men. Space limitations prevent focusing particularly on gender issues. A general pattern concerning gender issues, however, was that the men often showed more discomfort (long pauses in the conversations, nervous giggling, etc.) when the health consultant posed questions about their personal and private situation than women. Women were generally more eager to cooperate concerning the health consultant's choice of method and the issues to be discussed.

4 In a forthcoming article, I focus on the assumption that overweight people lack self-control and willpower; here, I focus on the interactional work that defines overweight people - in a more general sense - as psychologically abnormal.

\section{REFERENCES}

Adkins, L. (1995) Gendered Work: Sexuality, Family and the Labour Market. Buckingham: Open University Press. 
Blaikie, A., Hepworth, M., Holmes, M., Howson, A. and Inglis, D. (2004) ‘General Introduction: The Sociology of the Body: Genesis, Development and Futures', in Blaikie A., Hepworth M., Holmes M., Howson A. and Inglis D. (eds) The Body. London: Routledge, 1-23.

Bordo, S. (1993) Unbearable Weight: Feminism, Western Culture, and the Body. Berkeley, CA: University of California Press.

Brown, A. D. (2001) 'Organization Studies and Identity: Towards a Research Agenda', Human Relations 54: $113-21$

Butler, A., Ford, D. and Tregaskis, C. (2007) 'Who Do We Think We Are?: Self and Reflexivity an Social Work Practice', Qualitative Social Work 6(3): 281-99.

Collins, R. (2004) Interaction Ritual Chains. Princeton, NJ: Princeton University Press.

Czarniawska-Joerges, B. and Jacobsson, B. (1995) 'Political Organizations and Commedial Dell'Arte', Organizational Studies 16: 375-94.

Danish Ministry of the Interior and Health (2002) Sund Hele Livet [Healthy All Life]. Copenhagen: The Ministry of Interior and Health.

Deitch, E. A., Barsky, A., Butz, R. M., Chan, S., Brief, A. P. and Bradley, J. C. (2003) 'Subtle Yet Significant: The Existence and Impact of Everyday Racial Discrimination in the Workplace', Human Relations 5(54): 561-84.

Dick, P. (2005) 'Dirty Work Designations: How Police Officers Account for their Use of Coercive Force', Human Relations 58: 1363-90.

Douglas, M. (1999) Implicit Meanings. London: Routledge \& Kegan Paul.

Down, S. and Reveley, J. (2004) 'Generational Encounters and the Social Formation of Entrepreneurial Identity: "Young Guns" and "Old Farts', Organization 11(2): 233-50.

Gabriel, Y. (1999) 'Beyond Happy Families: A Critical Reevaluation of the Control-Resistance-Identity Triangle', Human Relations 52: 179-203.

Goffman, E. (1965) Stigma. Englewood Cliffs, NJ: Prentice-Hall.

Goffman, E. (1967) Interaction Ritual. New York: Doubleday. 
Goffman, E. (1983) ‘The Interactional Order’, American Sociological Review 48: 1-17. Goffman, E. (1990) The Presentation of Self in Everyday Life. London: Penguin Books. Greco, M. (2004) 'The Politics of Indeterminacy and the Right to Health', Theory, Culture \& Society 21(6): 1-22.

Gubrium, J. F. and Holstein, J. A. (eds) (2001) Institutional Selves: Troubled Identities in Organizational Context. Oxford: Oxford University Press.

Hassard, J., Holliday, R. and Willmott, H. (2000) 'Introduction: The Body and Organization', in Hassard J., Holliday R. and Willmott H. (eds) Body and Organization. London: SAGE, 1-14.

Hatch, M. J. and Schultz, M. (2002) ‘The Dynamics of Organizational Identity', Human Relations 55: $989-$ 1018.

Heracleous, L. and Marshak, R. J. (2004) 'Conceptualizing Organizational Discourse as Situated Symbolic Action', Human Relations 57: 1285-312.

Herdon, A. M. (2005) 'Collateral Damage from Friendly Fire?: Race, Nation, Class and the "War Against Obesity",, Social Semiotics 15(2): 127-41.

Hjo“rne, E. (2005) 'Negotiating the “Problem-child”' in School. Child Identity, Parenting and Institutional Agendas', Qualitative Social Work 4(4): 489-507.

Holstein, J. A. and Gubrium, J. F. (1997) ‘Active Interviewing’, in Silverman D. (ed.) Qualitative Research. Theory, Method and Practice. London: SAGE, 113-30.

Holstein, J. A. and Gubrium, J. F. (2000) The Self We Live By: Narrative Identity in a Postmodern World. Oxford: Oxford University Press.

Juhila, K. (2004) 'Talking Back to Stigmatized Identities. Negotiation of Culturally Dominant Categorizations in Interviews with Shelter Residents', Qualitative Social Work 3(3): 259-75.

Jutel, A. (2005) ‘Weighing Health: The Moral Burden of Obesity', Social Semiotics 15(2): 113-25.

LeBesco, K. (2004) Revolting Bodies?: The Struggle to Redefine Fat Identity. Boston, MA: University of Massachusetts Press.

Maines, D. R. (2003) ‘Interactionism’s Place’, Symbolic Interaction 26(1): 5-18.

Mead, G. H. (1959) Mind, Self and Society from the Standpoint of a Social Behaviorist. Chicago, IL: University of Chicago Press. 
Mik-Meyer, N. (2007) ‘Interpersonal Relations or Jokes of Social Structure?: Laughter in social work’, Qualitative Social Work 6(1): 9-26.

Mik-Meyer, N. (2010) ‘An Illness of One’s Own. Power and the negotiation of identity among social workers, doctors and patients without a bio-medical diagnosis', Journal of Power 3(2): 171-87.

Monaghan, L. F. (2005) 'Big Handsome Men, Bears and Others: Virtual Constructions of " Fat Male Embodiment",, Body \& Society 11(2): 81-111.

Murray, S. (2005) ‘(Un/Be)Coming Out? Rethinking Fat Politics’, Social Semiotics 15(2): 153-63.

National Obesity Forum (2007) http://www.nationalobesityforum.org.uk (consulted Jan. 2008).

Novas, C. and Rose, N. (2000) 'Genetic Risk and the Birth of the Somatic Individual', Economy and Society 29(4): 485-513.

Orbach, S. (1978) Fat Is a Feminist Issue. New York: Berkley Books.

Rose, N. (2001) 'The Politics of Life Itself', Theory, Culture \& Society 18(6): 1-30.

Samra-Fredericks, D. (2004) 'Managerial Elites Making Rhetorical and Linguistic “Moves” for a Moving (Emotional) Display', Human Relations 57: 1103-43.

Shilling, C. (1994) The Body and Social Theory. London: SAGE.

Steyrer, J. (1998) 'Charisma and the Archetypes of Leadership', Organizational Studies 19: 807-28.

Townsley, N. C. (2003) 'Review Article: Looking Back, Looking Forward. Mapping the Gendered Theories, Voices, and Politics of Organization', Organization 10(3): 617-39.

Trethewey, A. (1999) ‘Disciplined Bodies: Women's Embodied Identities at Work', Organizational Studies 20(3): 423-50.

Turner, B. (1992) Regulating Bodies: Essays in Medical Sociology. London: Routledge.

Turner, B. (2003) ‘Social Fluids: Metaphors and Meanings of Society’, Body \& Society 9(1): 1-10.

Urek, M. (2005) 'Making a Case in Social Work: The Construction of an Unsuitable Mother', Qualitative Social Work 4(4): 451-67.

Valentine, G. (2002) 'In-corporations: Food, Bodies and Organizations’, Body \& Society 8(1): 1-20.

Ward, J. and Winstanley, D. (2003) 'The Absent Presence: Negative Space within Discourse and the Construction of Minority Sexual Identity in the Workplace', Human Relations 10(53): 1255-80. 
Wilson, F. (1996) ‘Research Note: Organizational Theory: Blind and Deaf to Gender?’ Organizational Studies 17(5): 825-42.

World Health Organization (2006) WHO European Ministerial Conference on Counteracting Obesity: European Charter on Counteracting Obesity. Copenhagen: WHO Regional Office for Europe. 